\title{
Mosquito cell lines: history, isolation, availability and application to assess the threat of arboviral transmission in the United Kingdom
}

\author{
Thomas Walker ${ }^{1,2}$, Claire L Jeffries ${ }^{1,2^{*}}$, Karen L Mansfield ${ }^{1}$ and Nicholas Johnson ${ }^{1}$
}

\begin{abstract}
Mosquitoes are highly effective vectors for transmission of human and animal pathogens. Understanding the relationship between pathogen and vector is vital in developing strategies to predict and prevent transmission. Cell lines derived from appropriate mosquito hosts provide a relatively simple tool for investigating the interaction between the host and viruses transmitted by mosquitoes. This review provides a brief overview of the development of mosquito cell lines, methods of isolation, their availability and application for investigating insect-virus interactions.
\end{abstract}

Keywords: Mosquitoes, Cell lines, Arboviruses, Vector competence

\section{Background}

Mosquitoes are responsible for the transmission of numerous infectious diseases including malaria, dengue fever, West Nile fever and Japanese encephalitis. Malaria is transmitted by Anopheles mosquitoes and results in the greatest mortality predominantly in Sub-Saharan Africa. In 2010, the World Health Organization estimated that there were 219 million cases (660,000 deaths) of malaria with 3.3 billion people at risk. Dengue is transmitted by Aedes mosquitoes and the incidence has grown dramatically with 50-100 million cases/year and 2.5 billion people at risk. Significant outbreaks of other mosquito-borne diseases such as Chikungunya, Japanese encephalitis and lymphatic filariasis impose a substantial burden on global health and economics in developing countries. Arboviral diseases transmitted by mosquitoes are a driver for poverty in much of the developing world and have shown an increase in incidence in the past few decades with major outbreaks occurring in previously non-endemic areas [1]. The geographical range of mosquito vector species, through changing environmental factors and international trade, has contributed to the increase in arboviral epidemics $[2,3]$. Cost-effective treatment and

\footnotetext{
* Correspondence: Claire.Jeffries@lshtm.ac.uk

${ }^{1}$ Animal Health and Veterinary Laboratories Agency, Woodham Lane, New Haw, Addlestone, Surrey KT15 3NB, UK

${ }^{2}$ Current address: London School of Hygiene and Tropical Medicine, Keppel Street, London WC1E 7HT, UK
}

prevention of mosquito-borne diseases is complicated by the diversity of pathogens, mosquito vector species and disease pathology. Strategies for prevention include vaccination, prophylaxis and vector control, although for some diseases such as dengue fever and West Nile fever, vector control is currently the only available strategy to prevent transmission.

The mosquito lifecycle in its simplest form is composed of a series of life stages beginning with eggs laid on or near water that hatch after a number of days into larvae. The larvae obtain nutrition predominantly through filterfeeding but predation on other larvae and small invertebrates also occurs for certain species. Mosquitoes develop through four instar phases, to form non-feeding pupae, which metamorphose into adults (Figure 1). Adult males emerge first, followed by females and mating occurs when females are 2-3 days old. Whilst both males and females can derive nutrition from nectar, in most species females require a blood meal to promote egg development through the acquisition of protein and iron from blood. This provides the opportunity for pathogen transmission, particularly as female mosquitoes take multiple feeds during their lifecycle. Cells can be obtained from each of these developmental stages to generate cell lines appropriate for each experimental approach.

In recent years, interest has developed in a number of areas associated with virus-mosquito interactions. One key area of research has been elucidation of the immune 


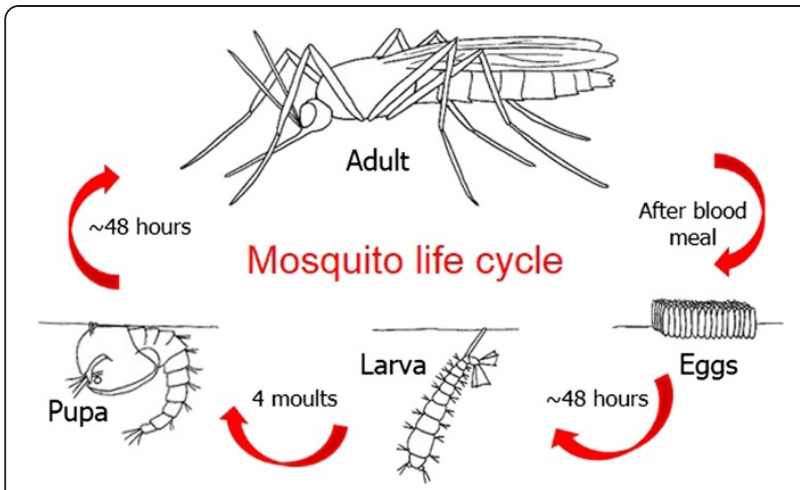

Figure 1 An illustration of the lifecycle of mosquitoes and potential sources of cell lines.

response of insects against pathogens, and viruses in particular. In contrast to vertebrates, which have developed the interferon system to suppress virus replication, insects have an alternative innate immune mechanism commonly referred to as RNA interference (RNAi). This immune mechanism in mosquitoes has been reviewed extensively in recent years [4,5]. Briefly, this virus control mechanism is stimulated by the presence of doublestranded RNA (an intermediary of virus replication) and leads to the recognition of specific sequences of singlestranded RNA (i.e. virus genomes) that are degraded by a cytoplasmic protein complex. Another area of research on mosquito-borne pathogens is to determine whether a given mosquito species is a potential vector for disease transmission. Vector competence studies can be undertaken in which infectious blood containing a pathogen is provided for the mosquito's blood meal, followed by an assessment of pathogen development within the mosquito. Transmission of mosquito-borne diseases requires the pathogen to undergo a significant period of time within the mosquito vector called the extrinsic incubation period (EIP). When a female mosquito bites an infectious human or animal, the pathogen is ingested with the blood meal and disseminates from the mosquito midgut, eventually reaching the mosquito's salivary glands for transmission to a new host. The time between ingestion of a blood meal and the ability to transmit virus is the EIP. The vectorial capacity of mosquitoes to transmit infectious pathogens depends on several factors including the EIP. For arboviruses such as dengue virus (DENV), the EIP is typically 7-14 days and external factors such as temperature can influence the EIP [6]. This experimental approach requires a range of skills and facilities including the ability to raise large numbers of mosquitoes (either colonised or wild caught), containment facilities for handling both the insect vector and the pathogen and expertise in both subjects. Therefore, alternative models to investigate vectorpathogen interactions are needed. In vitro studies using mosquito cell lines can be carried out to provide valuable information on aspects of these interactions. Here we review the history, isolation, availability and application of mosquito cell lines, and how cell lines can be used to contribute to understanding of the potential vector competence of UK mosquitoes for arboviruses.

\section{Review}

\section{History of mosquito cell culture}

There are over 500 insect cell lines now established from numerous insect orders including Diptera, Lepidoptera and Hemiptera, derived from different tissue sources $[7,8]$. The major mosquito disease vector species are within the Anopheles (An.), Culex (Cx.) and Aedes (Stegomyia) (Ae.) genera and several cell lines have been established. Table 1 contains a list of mosquito cell lines, which have been generated to our knowledge, with the associated disease transmitted by that species of mosquito. Early studies in the mid 1960s developed a generation of mosquito cell lines derived from larvae of the principal vector of DENV, Ae. aegypti [9]. The Ae. aegypti CCL-125 cell line was initially characterized as not susceptible to DENV [10]. However, more recent studies have come to the opposite conclusion and suggest that CCL-125 is permissive to DENV infection [11]. The Aag-2 cell line was also derived from Ae. aegypti in the late 1980s [12] and this cell line has been frequently used to study the mosquito immune system including the response to infection with Sindbis virus [13]. Subsequently Ae. aegypti cell lines such as RML-12 have been shown to be particularly susceptible to infection with DENV [14] and numerous other arboviruses including West Nile virus (WNV) and Japanese encephalitis virus (JEV) [15].

The Asian tiger mosquito, Ae. albopictus, is a competent vector of many arboviruses including DENV, Chikungunya virus [16] and Eastern equine encephalitis virus (EEEV) [17]. The first cell lines developed from Ae. albopictus, such as the C6/36 cell line (originally known as the ATC15 cell line), were generated from larvae in the mid 1960s [10]. Lineages of the C6/36 cell line have been widely used to study the relationship between arboviruses and mosquito vectors. Clones derived from the original cell line exhibited variable sensitivity to virus infection [18]. C6/ 36 cells were shown to be susceptible to a wide range of arboviruses, partially due to the lack of a functional RNAi response [19] and this cell line is now widely used to isolate arthropod-borne viruses. The C7-10 cell line was established from Ae. albopictus and has been shown to synthesize hormone-inducible proteins and thus forms a useful model for understanding hormone responses in insects [20].

Ae. pseudoscutellaris is a vector of subperiodic Wuchereria bancrofti, which is responsible for cases of human lymphatic filariasis in the South Pacific. A number of cell lines have been derived from larvae of this species in the 
Table 1 List of established mosquito cell cultures and associated mosquito-borne diseases

\begin{tabular}{|c|c|c|c|c|}
\hline Mosquito species & Disease transmission & Cell line & Source & Reference \\
\hline \multirow[t]{3}{*}{ Aedes aegypti } & Dengue virus & CCL-125 & Larvae & {$[10]$} \\
\hline & Yellow fever virus & Aag-2 & Embryos & {$[12]$} \\
\hline & & RML-12 & Larvae & [14] \\
\hline \multirow[t]{2}{*}{ Aedes albopictus } & Dengue virus & $\mathrm{C} 6 / 36$ & Larvae & [10] \\
\hline & & C7-10 & Larvae & {$[20]$} \\
\hline Aedes pseudoscutellaris & Lymphatic filariasis & AP-61 & Larvae & [14] \\
\hline \multirow[t]{2}{*}{ Aedes triseriatus } & La Crosse encephalitis virus & A.t. GRIP-1 & Embryos & {$[23]$} \\
\hline & & A.t. GRIP-2 \& -3 & Larvae & \\
\hline \multirow[t]{2}{*}{ Aedes vexans } & West Nile virus & UM-AVE1 & Embryos & {$[26]$} \\
\hline & Rift Valley fever virus & & & \\
\hline \multirow[t]{3}{*}{ Anopheles gambiae } & Malaria & Mos.55 & Larvae & {$[27]$} \\
\hline & & Sua1B & Larvae & {$[28]$} \\
\hline & & $4 a-3 B$ & Larvae & \\
\hline \multirow[t]{2}{*}{ Anopheles stephensi } & Malaria & Mos.43 & Larvae & [29] \\
\hline & & MSQ43 & Larvae & [30] \\
\hline Anopheles albimanus & Malaria & LSB-AA695BB & Embryos & {$[31]$} \\
\hline \multirow[t]{2}{*}{ Culex quinquefasciatus } & West Nile virus & Unnamed & Ovaries & [32] \\
\hline & Lymphatic filariasis & Unnamed & Embryos & [33] \\
\hline \multirow[t]{2}{*}{ Culex theileri } & Rift Valley fever virus & Unnamed & Embryos & [34] \\
\hline & Dog heartworm & & & \\
\hline Culex tritaeniorhynchus & Japanese encephalitis virus & NIID-CTR & Embryos & [36] \\
\hline Culex bitaeniorhynchus & Japanese encephalitis virus & Unnamed & Embryos & {$[37]$} \\
\hline Toxorhynchites amboinensis & - & TRA-171 & Larvae & {$[38]$} \\
\hline
\end{tabular}

1970s, and were shown to be susceptible to a range of arboviruses [21]. In particular, an Ae. pseudoscutellaris cell line, AP-61, was established and shown to be susceptible to DENV infection [14,22]. Another Aedes species, Ae. triseriatus, is a vector of La Crosse virus (LACV), which is a cause of encephalitis in the Midwest of the USA, and has been shown to be an efficient laboratory vector of EEEV. Three cell lines (A.t. GRIP-1, -2, and -3) were established from Ae. triseriatus embryos or larvae in the mid 1990s [23], and these cell lines have been shown to be susceptible to both LACV and snowshoe hare virus, a virus of wildlife that is exclusive to North America.

Ae. vexans mosquitoes are widespread throughout Europe and are potential vectors of WNV and RVFV $[24,25]$. A cell line, UM-AVE1, has been established from embryos of Ae. vexans [26] but susceptibility to arboviral infection has not been reported.

Anopheles mosquitoes, particularly species in the An. gambiae complex, are responsible for malaria in Sub-Saharan Africa. Malaria has the highest mortality rate of any mosquito-borne disease and is justifiably the main focus of research on mosquitoes as vectors of disease. Anopheles cell lines have been generated including An. gambiae Mos.55 [27], Sua1B and 4a-3B from larvae
[28]. The 4a-3B cell line is the first continuous insect cell line that produces prophenoloxidase, and is utilized as an in vitro model for the study of both the humoral and cellular immune defence of $A n$. gambiae mosquitoes. An. stephensi mosquitoes are the primary vectors of malaria in South Asia, and several cell lines have been generated from larvae including Mos.43 [29] and MSQ43 [30]. An. albimanus is a major malaria vector in Central and South America, and the LSB-AA695BB cell line has been established from An. albimanus embryos [31].

There are a number of Culex mosquitoes that are responsible for transmission of human diseases. Cx. quinquefasciatus is a member of the $C x$. pipiens complex and is the primary vector of Bancroftian lymphatic filariasis in tropical and sub-tropical regions. It is also the main vector of WNV in the USA and Europe. A cell line was established from this species using ovaries as the source tissue in the 1960s [32], and more recently a Cx. quinquefasciatus cell line has been established from embryos [33]. Cx. theileri is a natural vector of Dirofilaria immitis (dog heartworm) in southern Europe and is thought to be the major vector of Rift Valley fever virus (RVFV) in parts of southern Africa. A cell line was established for this vector species using embryos as the source material 
and was shown to be susceptible to a number of arboviruses [34]. Cx. tritaeniorhynchus mosquitoes are the principal vectors of JEV in Asia, and cell lines have also been established from embryos of this species [35,36]. The Cx. tritaeniorhynchus NIID-CTR cell line is highly susceptible to both JEV and DENV infection, and provides a valuable model for virus replication in the host [36]. Cx. bitaeniorhynchus, a mosquito found throughout Asia and a potential vector of JEV, has been used to generate cell lines that are susceptible to several arboviruses [37].

Toxorhynchites amboinensis has no known vector competence for human pathogens as this mosquito is unable to blood feed. This species has been used in mosquito biocontrol strategies, since the large predatory larvae eat other mosquito larvae such as Ae. aegypti. However, a cell line derived from Toxorhynchites amboinensis, TRA-171, has been established and shown to be susceptible to DENV infection, although the significance of this observation remains unclear [38].

\section{Isolation and generation of primary cell line cultures}

The source material for primary insect cell line culture is an important consideration. Ovaries were the first insect tissues used throughout the 1960s and 1970s, predominantly with Lepidoptera. Adult female mosquito tissues such as salivary glands or midguts could be used to generate cell lines that would be relevant to specific stages of virus-mosquito interactions that influence in vivo vector competence. For example, cell lines could be used to provide some preliminary information on the susceptibility of midgut or salivary gland cells prior to in vivo transmission studies. Embryos are now commonly used as the source for mosquito cell cultures as they contain cells with the potential to differentiate into larval and adult tissues, resulting in a wide diversity of cell morphologies.

A brief protocol for derivation of cells from mosquito embryos or tissues is detailed below.

- The protocol for cell culture generation from either embryos or female tissues such as ovaries requires adult female mosquitoes (4-5 days old) to be blood fed using standard procedures. Mosquito eggs are collected 4 days post-blood feed, when an egg laying pot is placed into the cage containing gravid females.

- Mosquito eggs are transferred from egg laying pots and rinsed thoroughly in $70 \%$ ethanol and then sterile water to prevent any bacterial contamination from the egg chorion (mosquito eggs are sufficiently impervious to simple disinfectants such as $70 \%$ ethanol). If tissues of adult female mosquitoes are used as the source material, tissues are dissected using sterile procedures.
- Embryos or tissues are mechanically disrupted in insect cell culture media using a tissue homogenizer such as a plastic pestle. Additional methods have been used to disrupt embryonic cells such as the use of bleach or using enzymes including trypsin.

However, care must be taken to avoid using chemicals that could potentially inhibit cell growth.

- Insect cell culture media can vary for different mosquito species but standard formulations include Grace's, Schneider's and Mitsuhashi and Maramorosch media. A typical cell medium for mosquito cells is supplemented with fetal bovine serum and the antibiotics penicillin/streptomycin to prevent bacterial contamination.

- The cell medium containing crushed mosquito material is then transferred to tissue culture flasks. Additional cell culture medium is added and cells are incubated at $26^{\circ} \mathrm{C}$ until cell attachment occurs. Culture medium is replaced every 3-4 days by vigorously shaking the tissue culture flasks and replacement with fresh medium.

- Subcultures are obtained by passaging cells continually through disrupting confluent cell monolayers and transferring cells in suspension to a new tissue culture flask with fresh medium. Observation of cell morphology, division and growth with an inverted microscope is used to generate several subcultures.

A large number of embryos can be obtained from laboratory mosquito colonies to provide source material for multiple cell line culture experiments. An important consideration in the use of embryos for cell culture is the timing of embryogenesis. An incubation period after egg laying of 16-20 hours (approximately 66\% of the time prior to larval hatching) was shown to be optimal for the successful generation of mosquito cell lines $[31,33]$. A change in temperature during incubation has also been shown to facilitate establishment of primary cell cultures, possibly through stimulation of cell division [34].

\section{Availability of mosquito cell lines}

The majority of cell lines currently used in arboviral research are obtained through direct contact with laboratories currently working with that particular cell culture. Only a few mosquito cell lines are commercially available. For example, the American Type Cell Collection only lists three cell lines derived from Ae. aegypti, Ae. albopictus and Toxorhynchites amboinensis (www.lgcstandards-atcc. org). The An. stephensi MSQ43 cell line is available from the Malaria Research and Reference Reagent Resource Center (www.mr4.org). Requests for mosquito cell lines can also be sent to the World Reference Centre for Emerging Viruses and Arboviruses (http://www.niaid.nih.gov/ labsandresources/resources/dmid/wrceva). 


\section{Application of mosquito cell lines}

In vitro serial cell line passage experiments can be used to determine the host range of arboviruses in mosquitoes, ticks and vertebrates $[39,40]$. In addition, insect cell lines can be used for protein expression analysis due to the post-translational processing and yield of expressed proteins in these eukaryotic cells. Various aspects of virus-mosquito host interactions can be investigated without the need for maintenance of insect colonies. For example, C6/36 mosquito cells have been used to demonstrate the cell entry mechanism of DENV [41]. Furthermore, defective DENV genomes have been detected in persistently infected C6/36 cells, providing valuable insight into the mechanisms through which arboviruses establish and maintain in vivo infections [42]. The antiviral immune response of Ae. aegypti to DENV infection has also been characterized in the immune-competent Aag2 cell line. Using transcriptomic analysis, it has been shown that DENV is capable of actively suppressing the mosquito immune response in infected cells [43]. Similarly, viral PIWI-interacting (pi)RNA-like molecules are produced following infection of mosquito cell lines with the mosquito-borne Semliki Forest virus, and have been shown to have anti-viral effects [44].

In vitro studies could be used to provide preliminary evidence for the potential of some mosquito species and vertebrate hosts to support replication of emerging arboviruses. For example, Rabensburg virus (RABV), a Flavivirus isolated from $C x$. pipiens, was first considered to be a potential new lineage of WNV [45], but it is now postulated to be an intermediate between the mosquitospecific and horizontally transmitted flaviviruses [46]. RABV did not infect mammalian or avian cell cultures but efficiently infected mosquito cells [46]. Furthermore, although $C x$. pipiens mosquitoes support replication of RABV, peroral transmission of infectious RABV was much lower, and vertical transmission higher, compared to WNV. Additionally, experimentally inoculated avian hosts did not become infected [46]. However, caution must be taken as in vitro vector-virus interaction may not always reflect in vivo vector competence or disease transmission in mosquito field populations.

Mosquito cell lines are also used extensively to passage arboviruses for in vivo transmission assays that involve collection of mosquito saliva during expectoration. Initially cell lines are used to amplify arbovirus titers required for oral feeding experiments. Mosquitoes presented with an arbovirus-infected blood meal undergo 'forced salivation', typically 7-14 days post-infection, to measure the length of the EIP of arboviruses within mosquitoes. Following forced salivation, mosquito cell lines such as C6/36 are inoculated with the collected saliva. Incubation of cells is then followed by an antibody-based detection protocol to determine whether infectious virus is present in saliva or through the appearance of plaque forming units. For low virus titers in saliva, several rounds of cell line passage may be undertaken to increase sensitivity.

Mosquito cell lines have also been used to determine the efficacy of novel compounds such as insecticides and biocontrol agents. Cell-based screening platforms have been developed to identify new compounds that are lethal to mosquito cell lines but show little or no activity against other insects (such as Drosophila) or human cell lines. Mosquitocidal cytotoxins were shown to be toxic to mosquito cells but not to Drosophila cells [47]. The gram positive bacterium Bacillus thuringiensis israelensis (Bti) produces insecticidal toxins active against mosquitoes that can be an effective larvicide for mosquito biocontrol. Cry4B is one of the major toxins produced by Bti and Aedes cell lines were used to demonstrate that Cry4B binds to several midgut membrane proteins including prohibitin, a protein recently identified as a receptor for entry of DENV into Aedes cells [48]. This study also utilized Aedes cells to show that pre-exposure to Cry $4 \mathrm{~B}$ results in a significant reduction in the number of infected cells compared to mock-exposed cells.

Mosquito-only flaviviruses (MOFs) have no known vertebrate reservoir host and have only been identified in mosquitoes. Cell lines have played an important role in the isolation and characterization of MOFs. The cell fusing agent virus was isolated in 1975 from an Ae. aegypti cell line [49]. Additional MOFs include Quang Binh virus isolated from $C x$. tritaeniorhynchus [50], Kamiti river virus from Ae. macintoshi [51,52], Nakiwogo virus from Mansonia africana [53] and Calbertado virus from $C x$. tarsalis [54-56]. Six potential MOFs were isolated from European mosquito species including five viruses that have not previously been reported in Ae. caspius, Cx. theileri, Ae. vexans and Ae. cinereus mosquitoes [57]. Inoculation of mosquito cell culture is often used to determine the presence of flavivirus isolates from wild mosquito material. A new virus, tentatively named Palm Creek virus, was isolated from Coquillettidia xanthogaster mosquitoes in Australia using infection of cultured mosquito cells [58]. Recently Aedes flavivirus (AEFV) strain SPFLD-MO-2011-MP6 was isolated in C6/36 cells from a pool of male Ae. albopictus mosquitoes that were reared to adults from larvae collected in the USA [59]. AEFV does not replicate in vertebrate cells, which is consistent with the lack of a vertebrate host range. Recently a new MOF from Ochlerotatus caspius mosquitoes was identified in Portugal and is referred to as Ochlerotatus flavivirus (OCFV) [60]. OCFV was also isolated in a C6/36 cell line where it replicated rapidly but failed to replicate in mammalian Vero cells.

Along with mosquitoes, other arthropods may also provide a useful source of cell lines for in vitro studies. Culicoides midges are important vectors of arboviruses such as bluetongue virus (BTV). Studies in Culicoides KC cell lines 
have demonstrated a functional RNAi response that inhibits BTV infection [61]. Tick cell lines have also been generated and have been used to study the response to tick-borne arboviruses of medical and veterinary importance. The susceptibility of cell lines from different tick species to Crimean-Congo hemorrhagic fever virus (CCHFV) revealed that there may be species-specific susceptibility to CCHFV infection [62].

\section{Cell lines from UK mosquito species}

Although several mosquito cell lines have been established from major mosquito disease vectors such as $A n$. gambiae (malaria) and Ae. aegypti (dengue), further cell lines are needed for native temperate mosquito species that are considered potential vectors of arboviruses. Sporadic WNV outbreaks have occurred in warmer regions of Europe for the past 20 years and could occur more frequently as a result of climate change [63]. $C x$. pipiens mosquitoes are widespread throughout Europe, and are critical vectors of WNV in the USA and southern Europe. Currently available cell lines, such as C6/36 and RML-12, are high passage cell lines, which may not be susceptible to many arboviruses that are considered a threat to countries such as the UK, including WNV. Ae. vexans is a vector of Tahyna virus and is the most common mosquito in Europe, but is relatively rare in the
UK. This species has also been shown to be a competent vector of both WNV and RVFV under laboratory conditions. Preliminary experiments have been undertaken to generate an Ae. vexans cell line from a colony of UK origin. As shown in Figure 2, evidence for cell line growth and adhesion to form a monolayer has been observed in early passages. This cell line will be used to determine the initial virus-vector interactions of Ae. vexans to a diverse range of arboviruses that are considered to be a potential threat to the UK and help to inform future in vivo vector competence studies.

There are over 30 endemic mosquito species in the UK and several, including $C x$. pipiens, which are potential WNV bridge vectors from birds to humans [64]. Furthermore, 12 species native to the UK, including $A e$. vexans and $C x$. modestus, have been shown to transmit WNV in other countries. Any change to the UK climate that causes an increase in mean temperature or prolonged periods of above-average warm weather may potentially increase the geographical distribution of European mosquitoborne diseases such as WNV. As a result, studies to determine the vector competence of mosquito species that are most likely to serve as bridge vectors for WNV are required to assess the likelihood of introduction and transmission in the UK. Investigation using mosquito cell lines will therefore provide a relatively simple method for deriving
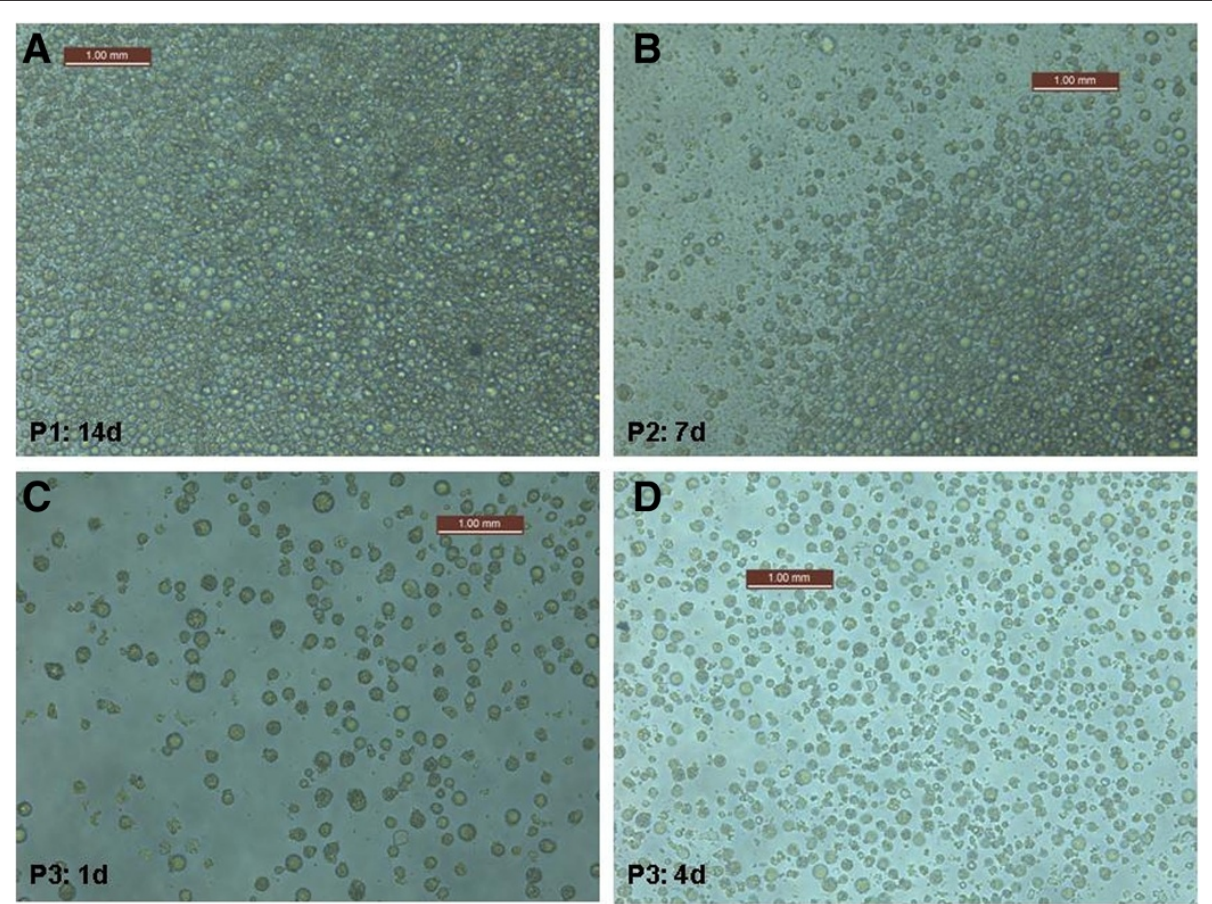

Figure 2 Generation of an Aedes vexans cell line of UK origin using embryos as the source material. The first passage ( $P$ ) was undertaken 14 days (d) after adding crushed embryos to cell media and P2 was undertaken 7d after P1 to allow cells to adhere. Routine passage of the cell line was undertaken from P3 by transferring 20\% cells in media to $80 \%$ media. A) P1 after 14d showing formation of a high density monolayer. B) P2 after 7d showing the start of a monolayer forming. C) P3 after 1d and D) P3 after 4d showing growth of the cell line. 
preliminary data on a range of virus-vector interactions with UK mosquito species. Cell lines that are shown to not be susceptible to certain viruses likely indicate that in vivo vector competence will be limited for that mosquito species. The genetic background of mosquito host vectors influences the vectorial capacity. Specific vector genotype $\mathrm{x}$ virus genotype $(G \times G)$ interactions may promote adaptation of viral lineages to local mosquito vector genotypes [65]. The virulence of arboviruses is particularly dependent on the mosquito host genetic background but can also influence host fitness. A trade-off hypothesis of virulence has been shown to significantly influence the evolution of arboviruses [66]. Virulence is also influenced by the genetic diversity of arboviruses. The introduction of genetic changes to arbovirus genomes that leads to genetic variation is thought to be limited by the requirement to replicate in both vertebrate and invertebrate hosts. Mosquito cell lines under laboratory conditions can be used to overcome this limitation allowing the introduction of genetic changes and determination of the effect on virulence. Alternative replication can be manipulated using both mammalian and mosquito cell lines. For example, passing Venezuelan equine encephalitis virus through cell lines resulted in nucleotide and amino acid changes but no significant change in virulence was observed [67]. Passing JEV under the same conditions resulted in 22 nucleotide and amino acid changes and attenuated virulence, with genetic changes occurring within 5 passages [67]. The evolution of vesicular stomatitis virus in either mammalian or insect cells was compared to alternating passages, with 7 mutations accumulating in alternated passages, compared to 2-4 for the constant cellular environment [68]. However, the authors of this study concluded that the slow rates of evolution observed in natural arbovirus populations are not necessarily due to the need for the virus to compromise between adaptation to both arthropod and vertebrate cell types. In contrast, a study carried out with DENV in a human cell line (Huh-7), the C6/36 mosquito cell line and alternating passages revealed that mutations accumulated more rapidly in viruses passed in Huh-7 cells than in those passed in C6/36 cells or in alternation [69]. Mosquito cell lines and alternating passages with mammalian cells can play a key role in trying to understand the patterns of arbovirus genetic evolution.

\section{Conclusions}

Experiments to determine virus-host interactions, with an appropriate cell line of UK genetic background, are necessary to assess the likely impact of the introduction of arboviral transmission in a new area and the ability of the pathogens to become established in the local mosquito population. The presence of insect-specific flaviviruses, particularly in mosquito populations, may also influence transmission of arboviruses to humans. For example, a laboratory colony of $C x$. pipiens established from Colorado, USA, has been shown to be infected with a Culex flavivirus (CxFV) and early suppression of WNV replication was observed [70]. However, another study demonstrated that $\mathrm{CxFV}$ had no significant impact on WNV replication, infection, dissemination or transmission in Cx. quinquefasciatus mosquitoes [71]. Establishment of cell lines from native UK $C x$. pipiens and Ae. vexans mosquitoes would provide suitable models to investigate insect-specific flaviviruses that are present in UK populations. Infection of cell lines with arboviruses such as WNV would provide valuable information to inform vector competence studies of these native mosquito species.

\section{Abbreviations}

RNAi: RNA interference; EIP: extrinsic incubation period; DENV: dengue virus; An:: Anopheles; Ae.: Aedes; Cx:: Culex; WNV: West Nile virus; JEV: Japanese encephalitis virus; EEEV: Eastern equine encephalitis virus; LACV: La Crosse virus; RVFV: Rift Valley fever virus; Bti: Bacillus thuringiensis israelensis: MOFs: Mosquito-only flaviviruses; AEFV: Aedes flavivirus; OCFV: Ochlerotatus flavivirus; BTV: Bluetongue virus; CCHFV: Crimean-Congo hemorrhagic fever virus; CXFV: Culex flavivirus.

\section{Competing interests}

The authors declare that they have no competing interests.

\section{Authors' contributions}

TW reviewed the literature. TW and CLJ performed mosquito cell line experiments. TW, CLJ, KLM and NJ wrote the paper. CL drew the illustrations and prepared Figure 1. All authors read and approved the final manuscript.

\section{Acknowledgements}

This review was funded through grant SE4112 from the Department of Environment Food and Rural Affairs (Defra, UK). We would like to thank Dr Colin Malcolm (Queen Mary University of London) for providing us with Ae. vexans colony eggs of UK origin. We would also like to thank Fiona $\mathrm{McCracken}$ (AHVLA) for her assistance in mosquito cell line experiments.

Received: 8 April 2014 Accepted: 6 August 2014

Published: 20 August 2014

\section{References}

1. Kyle $J$, Harris E: Global spread and persistence of dengue. Annu Rev Microbiol 2008, 62:71-92.

2. Jetten TH, Focks DA: Potential changes in the distribution of dengue transmission under climate warming. Am J Trop Med Hyg 1997, 57(3):285-297.

3. Reiter P: Yellow fever and dengue: a threat to Europe? Euro Surveill 2010, 15(10):19509.

4. Fragkoudis R, Attarzadeh-Yazdi G, Nash AA, Fazakerley JK, Kohl A: Advances in dissecting mosquito innate immune responses to arbovirus infection. J Gen Virol 2009, 90(Pt 9):2061-2072.

5. Blair CD: Mosquito RNAi is the major innate immune pathway controlling arbovirus infection and transmission. Future Microbiol 2011, 6(3):265-277.

6. Smith CE: The significance of mosquito longevity and blood-feeding behaviour in the dynamics of arbovirus infections. Med Biol 1975, 53(5):288-294.

7. Lynn DE: Available lepidopteran insect cell lines. Methods Mol Biol 2007, 388:117-138.

8. Smagghe G, Goodman CL, Stanley D: Insect cell culture and applications to research and pest management. In Vitro Cell Dev Biol Anim 2009, 45(3-4):93-105.

9. Grace TD: Establishment of a line of mosquito (Aedes aegypti L.) cells grown in vitro. Nature 1966, 211(5047):366-367.

10. Singh KRP: Cell cultures derived from larvae of Aedes albopictus (Skuse) and Aedes aegypti (L.). Curr Sci 1967, 36(19):506-508.

11. Wikan N, Kuadkitkan A, Smith DR: The Aedes aegypti cell line CCL-125 is dengue virus permissive. J Virol Methods 2009, 157(2):227-230. 
12. Lan $\mathrm{Q}$, Fallon $\mathrm{AM}$ : Small heat shock proteins distinguish between two mosquito species and confirm identity of their cell lines. Am J Trop Med Hyg 1990, 43(6):669-676.

13. Barletta $A B$, Silva MC, Sorgine $M H$ : Validation of Aedes aegypti Aag-2 cells as a model for insect immune studies. Parasit Vectors 2012, 5:148.

14. Kuno G: Cultivation of mosquito cell lines in serum-free media and their effects on dengue virus replication. In vitro 1983, 19(9):707-713.

15. Sudeep AB, Parashar D, Jadi RS, Basu A, Mokashi C, Arankalle VA, Mishra AC: Establishment and characterization of a new Aedes aegypti (L.) (Diptera: Culicidae) cell line with special emphasis on virus susceptibility. In Vitro Cell Dev Biol Anim 2009, 45(9):491-495.

16. Vega-Rua A, Zouache K, Caro V, Diancourt L, Delaunay P, Grandadam M, Failloux AB: High efficiency of temperate Aedes albopictus to transmit chikungunya and dengue viruses in the Southeast of France. PLoS One 2013, 8(3):e59716.

17. Mitchell CJ, Niebylski ML, Smith GC, Karabatsos N, Martin D, Mutebi JP, Craig $\mathrm{GB} \mathrm{Jr}$, Mahler MJ: Isolation of eastern equine encephalitis virus from Aedes albopictus in Florida. Science 1992, 257(5069):526-527.

18. Igarashi A: Isolation of a Singh's Aedes albopictus cell clone sensitive to Dengue and Chikungunya viruses. J Gen Virol 1978, 40(3):531-544.

19. Brackney DE, Scott JC, Sagawa F, Woodward JE, Miller NA, Schilkey FD, Mudge J, Wilusz J, Olson KE, Blair CD, Ebel GD: C6/36 Aedes albopictus cells have a dysfunctional antiviral RNA interference response. PLoS Negl Trop Dis 2010, 4(10):e856

20. Lan Q, Gerenday A, Fallon AM: Cultured Aedes albopictus mosquito cells synthesize hormone-inducible proteins. In Vitro Cell Dev Biol Anim 1993, 29A(10):813-818.

21. Varma MG, Pudney M, Leake CJ: Cell lines from larvae of Aedes (Stegomyia) malayensis Colless and Aedes (S) pseudoscutellaris (Theobald) and their infection with some arboviruses. Trans R Soc Trop Med Hyg 1974 68(5):374-382

22. Kuno G, Moore CG, Sather GE: Factors affecting syncytial development in Aedes pseudoscutellaris cells by dengue viruses. Am J Trop Med Hyg 1981 30(4):870-875

23. Charpentier G, Belloncik S, Ducros G, Fontenille D, Tian L, Quiot JM: Establishment and characterization of three cell lines from Aedes triseriatus (Diptera: Culicidae). J Med Entomol 1995, 32(6):793-800.

24. Fall AG, Diaite A, Etter E, Bouyer J, Ndiaye TD, Konate L: The mosquito Aedes (Aedimorphus) vexans arabiensis as a probable vector bridging the West Nile virus between birds and horses in Barkedji (Ferlo, Senegal). Med Vet Entomol 2012, 26(1):106-111.

25. Tiawsirisup S, Kinley JR, Tucker BJ, Evans RB, Rowley WA, Platt KB: Vector competence of Aedes vexans (Diptera: Culicidae) for West Nile virus and potential as an enzootic vector. J Med Entomol 2008, 45(3):452-457.

26. Mazzacano CA, Munderloh UG, Kurtti TJ: Characterization of a new continuous cell line from the flood water mosquito, Aedes vexans. Cytotechnolog 1991, 5(2):147-154.

27. Marhoul Z, Pudney M: A mosquito cell line (MOS. 55) from Anopheles gambiae larva. Trans R Soc Trop Med Hyg 1972, 66(1):183-184.

28. Muller HM, Dimopoulos G, Blass C, Kafatos FC: A hemocyte-like cell line established from the malaria vector Anopheles gambiae expresses six prophenoloxidase genes. J Biol Chem 1999, 274(17):11727-11735.

29. Pudney M, Varma MG: Anopheles stephensi var. mysorenis: establishment of a larval cell line (Mos. 43). Exp Parasitol 1971, 29(1):7-12.

30. Schneider I: Establishment of three diploid cell lines of Anopheles stephensi (Diptera: Culicidae). J Cell Biol 1969, 42(2):603-606.

31. Bello FJ, Brochero H, Boshell J, Olano V, Rey G: Establishment and characterization of a cell line from the mosquito Anopheles albimanus (Diptera: Culicidae). Mem Inst Oswaldo Cruz 1997, 92(1):123-128.

32. Hsu SH, Mao WH, Cross JH: Establishment of a line of cells derived from ovarian tissue of Culex quinquefasciatus Say. J Med Entomol 1970, 7(6):703-707.

33. Segura NA, Santamaria E, Cabrera OL, Bello F: Establishment and characterisation of a new cell line derived from Culex quinquefasciatus (Diptera: Culicidae). Mem Inst Oswaldo Cruz 2012, 107(1):89-95.

34. Oelofsen MJ, Gericke A, Smith MS, van der Linde TC: Establishment and characterization of a cell line from the mosquito Culex (Culex) theileri (Diptera: Culicidae) and its susceptibility to infection with arboviruses. J Med Entomol 1990, 27(6):939-944.

35. Athawale SS, Sudeep AB, Barde PV, Jadi R, Pant U, Mishra AC, Mourya DT: A new cell line from the embryonic tissues of Culex tritaeniorhynchus and its susceptibility to certain flaviviruses. Acta Virol 2002, 46(4):237-240.
36. Kuwata R, Hoshino K, Isawa H, Tsuda Y, Tajima S, Sasaki T, Takasaki T, Kobayashi M, Sawabe K: Establishment and characterization of a cell line from the mosquito Culex tritaeniorhynchus (Diptera: Culicidae). In Vitro Cell Dev Biol Anim 2012, 48(6):369-376.

37. Pant U, Banerjee K, Athawale SA, Dhanda V: Susceptibility of Culex bitaeniorhynchus cell line to some arboviruses. Indian J Med Res 1982 76:789-794.

38. Kuno G: Persistent infection of a nonvector mosquito cell line (TRA-171) with dengue viruses. Intervirology 1982, 18(1-2):45-55.

39. Kuno G: Host range specificity of flaviviruses: correlation with in vitro replication. J Med Entomol 2007, 44(1):93-101.

40. Lawrie CH, Uzcategui NY, Armesto M, Bell-Sakyi L, Gould EA: Susceptibility of mosquito and tick cell lines to infection with various flaviviruses. Med Vet Entomol 2004, 18(3):268-274.

41. Acosta EG, Castilla V, Damonte EB: Infectious dengue-1 virus entry into mosquito C6/36 cells. Virus Res 2011, 160(1-2):173-179.

42. Juarez-Martinez AB, Vega-Almeida TO, Salas-Benito M, Garcia-Espitia M, De Nova-Ocampo M, Del Angel RM, Salas-Benito JS: Detection and sequencing of defective viral genomes in C6/36 cells persistently infected with dengue virus 2. Arch Virol 2013, 158(3):583-599.

43. Sim S, Dimopoulos G: Dengue virus inhibits immune responses in Aedes aegypti cells. PLoS One 2010, 5(5):e10678.

44. Schnettler E, Donald CL, Human S, Watson M, Siu RW, McFarlane M, Fazakerley JK, Kohl A, Fragkoudis R: Knockdown of piRNA pathway proteins results in enhanced Semliki Forest virus production in mosquito cells. J Gen Virol 2013, 94(Pt 7):1680-1689.

45. Bakonyi T, Hubalek Z, Rudolf I, Nowotny N: Novel flavivirus or new lineage of West Nile virus, central Europe. Emerg Infect Dis 2005, 11(2):225-231.

46. Aliota MT, Jones SA, Dupuis AP 2nd, Ciota AT, Hubalek Z, Kramer LD: Characterization of Rabensburg virus, a flavivirus closely related to West Nile virus of the Japanese encephalitis antigenic group. PLoS One 2012, 7(6):e39387.

47. O'Neal MA, Posner BA, Coates CJ, Abrams JM: A cell-based screening platform identifies novel mosquitocidal toxins. J Biomol Screen 2013, 18(6):688-694.

48. Kuadkitkan A, Smith DR, Berry C: Investigation of the Cry4B-prohibitin interaction in Aedes aegypti cells. Curr Microbiol 2012, 65(4):446-454.

49. Stollar $\mathrm{V}$, Thomas VL: An agent in the Aedes aegypti cell line (Peleg) which causes fusion of Aedes albopictus cells. Virology 1975, 64(2):367-377.

50. Crabtree MB, Nga PT, Miller BR: Isolation and characterization of a new mosquito flavivirus, Quang Binh virus, from Vietnam. Arch Virol 2009, 154(5):857-860.

51. Crabtree MB, Sang RC, Stollar V, Dunster LM, Miller BR: Genetic and phenotypic characterization of the newly described insect flavivirus. Kamiti River virus Arch Virol 2003, 148(6):1095-1118.

52. Sang RC, Gichogo A, Gachoya J, Dunster MD, Ofula V, Hunt AR, Crabtree $M B$, Miller BR, Dunster LM: Isolation of a new flavivirus related to cell fusing agent virus (CFAV) from field-collected flood-water Aedes mosquitoes sampled from a dambo in central Kenya. Arch Virol 2003, 148(6):1085-1093.

53. Cook S, Moureau G, Harbach RE, Mukwaya L, Goodger K, Ssenfuka F, Gould E, Holmes EC, de Lamballerie X: Isolation of a novel species of flavivirus and a new strain of Culex flavivirus (Flaviviridae) from a natural mosquito population in Uganda. J Gen Virol 2009, 90(Pt 11):2669-2678.

54. Bolling BG, Eisen L, Moore CG, Blair CD: Insect-specific flaviviruses from Culex mosquitoes in Colorado, with evidence of vertical transmission. Am J Trop Med Hyg 2011, 85(1):169-177.

55. Pabbaraju K, Ho KC, Wong S, Fox JD, Kaplen B, Tyler S, Drebot M, Tilley PA: Surveillance of mosquito-borne viruses in Alberta using reverse transcription polymerase chain reaction with generic primers. J Med Entomol 2009, 46(3):640-648.

56. Tyler S, Bolling BG, Blair CD, Brault AC, Pabbaraju K, Armijos MV, Clark DC, Calisher $\mathrm{CH}$, Drebot MA: Distribution and phylogenetic comparisons of a novel mosquito flavivirus sequence present in Culex tarsalis mosquitoes from western Canada with viruses isolated in California and Colorado. Am J Trop Med Hyg 2011, 85(1):162-168.

57. Calzolari M, Ze-Ze L, Ruzek D, Vazquez A, Jeffries C, Defilippo F, Osorio HC, Kilian P, Ruiz S, Fooks AR, Maioli G, Amaro F, Tlusty M, Figuerola J, Medlock JM, Bonilauri P, Alves MJ, Sebesta O, Tenorio A, Vaux AG, Bellini R, Gelbic I, Sanchez-Seco MP, Johnson N, Dottori M: Detection of mosquito-only flaviviruses in Europe. J Gen Virol 2012, 93(Pt 6):1215-1225 
58. Hobson-Peters J, Yam AW, Lu JW, Setoh YX, May FJ, Kurucz N, Walsh S, Prow NA, Davis SS, Weir R, Melville L, Hunt N, Webb RI, Blitvich BJ, Whelan $P$, Hall RA: A new insect-specific flavivirus from northern Australia suppresses replication of West Nile virus and Murray Valley encephalitis virus in co-infected mosquito cells. PLoS One 2013, 8(2):e56534.

59. Haddow AD, Guzman H, Popov VL, Wood TG, Widen SG, Tesh RB, Weaver SC: First isolation of Aedes flavivirus in the Western Hemisphere and evidence of vertical transmission in the mosquito Aedes (Stegomyia) albopictus (Diptera: Culicidae). Virology 2013, 440(2):134-139.

60. Ferreira DD, Cook S, Lopes A, de Matos AP, Esteves A, Abecasis A, de Almeida AP, Piedade J, Parreira R: Characterization of an insect-specific flavivirus (OCFV) co-isolated from Ochlerotatus caspius collected in southern Portugal along with a putative new Negev-like virus. Virus Genes 2013, 47(3):532-545

61. Schnettler E, Ratinier M, Watson M, Shaw AE, McFarlane M, Varela M, Elliott RM, Palmarini M, Kohl A: RNA interference targets arbovirus replication in Culicoides cells. J Virol 2013, 87(5):2441-2454.

62. Bell-Sakyi L, Kohl A, Bente DA, Fazakerley JK: Tick cell lines for study of Crimean-Congo hemorrhagic fever virus and other arboviruses. Vector Borne Zoonotic Dis 2012, 12(9):769-781.

63. Sambri V, Capobianchi M, Charrel R, Fyodorova M, Gaibani P, Gould E, Niedrig M, Papa A, Pierro A, Rossini G, Varani S, Vocale C, Landini MP: West Nile virus in Europe: emergence, epidemiology, diagnosis, treatment, and prevention. Clin Microbiol Infect 2013, 19(8):699-704.

64. Medlock JM, Snow KR, Leach S: Potential transmission of West Nile virus in the British Isles: an ecological review of candidate mosquito bridge vectors. Med Vet Entomol 2005, 19(1):2-21.

65. Lambrechts L, Chevillon C, Albright RG, Thaisomboonsuk B, Richardson JH, Jarman RG, Scott TW: Genetic specificity and potential for local adaptation between dengue viruses and mosquito vectors. BMC Evol Biol 2009, 9:160.

66. Ciota AT, Ehrbar DJ, Matacchiero AC, Van Slyke GA, Kramer LD: The evolution of virulence of West Nile virus in a mosquito vector: implications for arbovirus adaptation and evolution. BMC Evol Biol 2013, 13:71.

67. McCurdy K, Joyce J, Hamilton S, Nevins C, Sosna W, Puricelli K, Rayner JO: Differential accumulation of genetic and phenotypic changes in Venezuelan equine encephalitis virus and Japanese encephalitis virus following passage in vitro and in vivo. Virology 2011, 415(1):20-29.

68. Novella IS, Hershey CL, Escarmis C, Domingo E, Holland JJ: Lack of evolutionary stasis during alternating replication of an arbovirus in insect and mammalian cells. J Mol Biol 1999, 287(3):459-465.

69. Vasilakis N, Deardorff ER, Kenney JL, Rossi SL, Hanley KA, Weaver SC: Mosquitoes put the brake on arbovirus evolution: experimental evolution reveals slower mutation accumulation in mosquito than vertebrate cells. PLoS Pathog 2009, 5(6):e1000467.

70. Bolling BG, Olea-Popelka FJ, Eisen L, Moore CG, Blair CD: Transmission dynamics of an insect-specific flavivirus in a naturally infected Culex pipiens laboratory colony and effects of co-infection on vector competence for West Nile virus. Virology 2012, 427(2):90-97.

71. Kent RJ, Crabtree MB, Miller BR: Transmission of West Nile virus by Culex quinquefasciatus say infected with Culex Flavivirus Izabal. PLoS Negl Trop Dis 2010, 4(5):e671.

doi:10.1186/1756-3305-7-382

Cite this article as: Walker et al: Mosquito cell lines: history, isolation, availability and application to assess the threat of arboviral transmission in the United Kingdom. Parasites \& Vectors 2014 7:382.

\section{Submit your next manuscript to BioMed Central and take full advantage of:}

- Convenient online submission

- Thorough peer review

- No space constraints or color figure charges

- Immediate publication on acceptance

- Inclusion in PubMed, CAS, Scopus and Google Scholar

- Research which is freely available for redistribution

Submit your manuscript at www.biomedcentral.com/submit
( Biomed Central 